\section{Spray-induced gene silencing: an innovative strategy for plant trait improvement and disease control}

\section{Ramesh R. Vetukuri ${ }^{1 *}$, Mukesh Dubey ${ }^{2}$, Pruthvi B. Kalyandurg ${ }^{1}$, Anders S. Carlsson ${ }^{1}$, Stephen C. Whisson ${ }^{3}$ and Rodomiro Ortiz ${ }^{1}$}

\begin{abstract}
Modern plant breeding is still a time-consuming and costly process, even with the most advanced technologies such as gene editing. Hence, there is an urgent need to develop alternative means for plant trait manipulation and plant protection. RNA interference (RNAi) is a conserved cellular mechanism mediated by naturally occurring double-stranded RNA (dsRNA) and small RNAs (sRNAs) that can target mRNAs for destruction or transcript reduction. Here, we review the potential of technology based on RNAi, called spray-induced gene silencing (SIGS), as an alternative or adjunct to breeding for manipulation of endogenous gene expression in plants or pathogen control. SIGS based on exogenous application of RNA molecules in plants may be especially useful in reducing pest or pathogen impacts, thereby ameliorating biotic stresses and increasing the agronomic performance of crops.
\end{abstract}

Keywords: RNA interference, small RNAs, SIGS, dsRNAs

\section{INTRODUCTION}

Over the last century, global food demand has increased due to the quadrupling of the human population from 1.8 billion people in 1915 to 7.9 billion at present and is expected to rech 9.7 billion by 2050 (UN 2019). To meet the growing population demands, food production needs to increase by $98 \%$ by 2050 despite challenges such as pests, pathogens, climate change and urbanization (Valin et al. 2014). Global food production demands can only be met by integrating modern breeding and plant biotechnological tools for precision farming to maximize edible yields and minimize losses to both biotic and abiotic stresses. Modern precision breeding technologies of introducing genes into elite germplasm using the most advanced technologies such as gene editing and speed breeding will still require years to deliver individual improved cultivars. Furthermore, not all crop plants are amenable to genetic modification with tools such as gene editing, or they have breeding cycles that require years between crosses and subsequent phenotyping (e.g. trees).

Today, bringing a transgenic crop from development to commercialization costs US\$140 million (Rosa et al. 2018). There is also public opposition and legislative limitations on cultivation of genetically modified (GM) crops in many countries (particularly in Africa, most of Asia, and Europe). Similarly, to bring a new synthetic crop protection chemical to market costs over US\$250 million and takes over 10 years (Sparks and Lorsbach 2017). Thus there is a need to develop
Crop Breeding and Applied Biotechnology 21(S): e387921S11, 2021 Brazilian Society of Plant Breeding. Printed in Brazil http://dx.doi.org/10.1590/198470332021v21Sa24

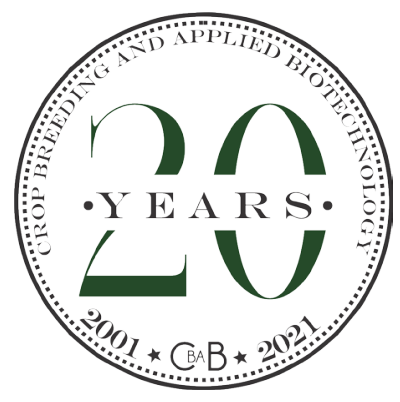

*Corresponding author: E-mail: ramesh.vetukuri@slu.se (iD) ORCID: 0000-0001-7129-5326

Received: 25 June 2021 Accepted: 27 June 2021 Published: 06 July 2021

${ }^{1}$ Swedish University of Agricultural Sciences, Department of Plant Breeding, Horticum, Alnarp, Sweden

${ }^{2}$ Uppsala Biocenter, Swedish University of Agricultural Sciences, Department of Forest Mycology and Plant Pathology, Uppsala, Sweden

${ }^{3}$ The James Hutton Institute, Cell and Molecular Sciences, Invergowrie, Dundee, UK 
new sustainable and GMO-free approaches to improve plant traits and agronomic performance, that support and work in parallel with modern breeding. Research elsewhere has shown that gene silencing approaches can aid precision breeding and plant protection via manipulation of plant traits involved in growth and different stress tolerances (biotic and abiotic) (Younis et al. 2014). In particular, the strategy of spray induced gene silencing (SIGS), which uses topical application of double stranded RNA (dsRNA) molecules, has an advantage of being more environmentally acceptable and GMO-free. In this review, RNAi approaches involving topical application of RNA molecules directly on plants (SIGS) are discussed (Figure 1).

\section{REGULATION OF PLANT TRAITS VIA TOPICAL APPLICATION OF RNAS}

Small non-coding RNAs (sRNAs) of 20-40 nucleotides (nt) have emerged as key players in transcriptional and post-transcriptional gene regulation, also known as RNA interference (RNAi), in an array of organisms (Ghildiyal and Zamore 2009, Holoch and Moazed 2015, Dalakouras et al. 2020). RNA silencing or RNAi is a conserved eukaryotic process in which transcript accumulation is either modulated or reduced in a sequence-specific manner. sRNAs, through RNAi, play important roles in gene regulation, genome stability, chromatin organization, and pathogen/ pest resistance (Ding 2010, Ketting 2011, Castel and Martienssen 2013). The biogenesis and function of sRNAs typically involves the processing of dsRNAs by a core set of proteins, namely Dicer or Dicer-like (DCR or DCL; double-stranded (ds)RNA ribonuclease), Argonaute (AGO; RNA binding, slicer ribonuclease), and RNA-dependent RNA polymerase (RdR; secondary sRNA production) (Holoch and Moazed 2015). The sRNAs move from their site of biogenesis to neighboring cells across plasmodesmata, the nano-channels that allow cell continuity in plants, or apoplastically through intercellular spaces (Mermigka et al. 2016). The sRNAs can also be transported long-distance to distal parts of the plant through the vasculature, a process termed systemic RNAi (Melnyk et al. 2011). As a result of their role in regulating the developmental pathways of eukaryotic organisms, there has been an increasing interest in exploiting sRNAs to modulate plant gene expression towards improving crop productivity and enhancing stress tolerance.

RNA-based applications have been reported to effectively target plant transgenes and endogenous genes in only a few plant systems such as Nicotiana benthamiana, Arabidopsis and rice through various methods, including formulations with adjuvants to enhance dsRNA delivery, syringe infiltrations, foliar spraying, and irrigation methods. In one of the first reports utilizing SIGS technology, N. benthamiana leaves were treated with 200 bp and 700 bp dsRNA, 21-nt sRNA, or 21-mer anti-sense ssDNA targeting an endogenous PHYTOENE DESATURASE (PDS) gene, resulting in bleaching of leaves within ten days (Sammons et al. 2011). In this study, leaves were treated either with carborundum or Silwet L-77 surfactant as an adjuvant before dsRNA application.

Syringe infiltration is considered as one of the simplest methods for introducing transgenes in model plants. Surprisingly though, leaf infiltration with dsRNA targeting a YFP transgene in Arabidopsis did not result in RNAi. However, delivery of dsRNA through a carrier complex containing a copolymer of histidine and lysine along with a cell-penetrating peptide resulted in efficient delivery of dsRNA targeting the YFP transgene and an endogenous CHALCONE SYNTHASE (CHS) gene, followed by decreased mRNA accumulation for the respective genes (Numata et al. 2014). The Cy3-labelled dsRNA was observed in the cytosol, indicating that symplastic delivery of dsRNA is important for effective dsRNA-mediated target gene silencing. Similarly, Jiang et al. (2014) reported that cationic fluorescent nanoparticle-based formulation of dsRNA ( $\mathrm{G} 2$ nanoparticle-dsRNA at 2:1 ratio) effectively delivered the dsRNA into plant cells. Application of G2-dsRNA targeting 
SHOOT MERISTEMLESS (STM), a gene required for formation and maintenance of shoot apical meristem, and WEREWOLF (WER), a transcription factor (TF) involved in specifying non-hair identity in the root epidermis, were applied for three subsequent days at the root tip, resulting in reduction in transcription levels by $84 \%$ and $87 \%$, respectively, compared to mock or water treated controls (Jiang et al. 2014). These reports demonstrate that accumulation of specific mRNAs can be targeted by exogenously applied dsRNAs in both above and below ground plant parts, but that the uptake of the dsRNA can be strongly influenced by the formulation.

In addition to carrier-based formulations, mechanical inoculation through spreading of dsRNA with soft sterile brushes and gentle rub inoculation also has been shown to aid dsRNA delivery to induce RNAi. Application of dsRNA targeting eGFP and NEOMYCIN PHOSPHOTRANSFERASE II (NPTII) in transgenic Arabidopsis plants using soft brushes resulted in significant reduction in the target transcript and protein levels (Dubrovina et al. 2019). Gentle rub inoculation of dsRNA targeting MYB1, a TF involved in flower morphogenesis, onto the floral buds of the orchid plant Dendrobium hybrida resulted in formation of flattened epidermal cells compared to conical shaped cells (Lau et al. 2015). The authors of this study used crude bacterial extracts containing a $430 \mathrm{bp}$ dsRNA targeting MYB1, expanding the scope of dsRNAbased strategies in manipulating plant traits, by potentially enabling large scale application. However, application of dsRNAs through rub inoculation, or infiltration-based methods are not suitable at a large greenhouse or field scale. Such limitations can be overcome through irrigation or spray-based technologies.

Promising research results were obtained after roots of two-week old Arabidopsis seedlings soaked in $1 \mathrm{~mL}$ of a $~ 500$ bp dsRNA targeting MOB KINASE ACTIVATOR-LIKE 1A (MOB1A), gene involved in tissue patterning and organ growth, and WRKY23, a TF involved in auxin mediated root development resulted in absorption of dsRNA. As expected, dsRNA ${ }^{\text {Mob1A }}$ caused suppression of flowering, while dsRNA ${ }^{W R K Y 23}$ resulted in impaired root growth (Li et al. 2015). To further examine the possibility of uptake of dsRNA through the root system, Li et al. (2015) submerged the roots of three-leaf rice plants in fluorescently-labelled dsRNA ${ }^{\text {eYFP }}$ and dsRNA ${ }^{A c t i n}$. In line with their previous observation, fluorescence was observed in the rice sheath and growth was severely repressed in dsRNA ${ }^{\text {Actin }}$ treated plants. The expression levels of Ago and Dicer were also upregulated, suggesting the activation of the RNAi pathway (Li et al. 2015). Taken together, the authors provide evidence for successful absorption of dsRNA through irrigation systems, a step towards modulating endogenous traits. That this research led to clear phenotypic changes indicates the scope for RNAi, initiated by exogenously applied dsRNA, for regulating plant endogenous genes. However, there is a pressing need for more research to corroborate these findings in other plant systems and using a large-scale approach. Delivery of dsRNAs via irrigation would be particularly well suited to crops grown under hydroponic conditions.

Following patent WO 2011/112570 describing that dsRNAs, small interfering RNAs (siRNAs) and single stranded DNA oligonucleotides can trigger efficient local and systemic silencing of $N$. benthamiana endogenes, foliar application of dsRNA for targeting endogenous genes has attracted interest in the agricultural community (Sammons et al. 2011). However, low-pressure spraying of siRNA GFP on transgenic N. benthamiana $16 \mathrm{C}$ plants did not result in GFP silencing, probably owing to failure in achieving symplastic entry (Dalakouras et al. 2016). This problem was overcome by using high-pressure spraying of siRNAs targeting GFP, although silencing was only achieved in a few cells. Further research is necessary to establish whether high-pressure spraying is functional in targeting plant endogenous genes, or if dsRNA uptake from spray application can be improved through addition of adjuvants to the dsRNA formulation.

\section{CROP TRAITS FOR MODULATION BY SIGS}

Since RNAi functions to remove the target mRNA from the transcriptome, it is particularly well suited to modulation of plant traits where negative regulators have a significant impact on plant phenotype. That is, plant genes that, when the mRNAs are knocked down, lead to an advantageous phenotype. Examples of traits where SIGS targeting negative regulators could improve crop performance include: drought and salinity tolerance (Feng et al. 2021, Li et al. 2021, Min et al. 2021, Myo et al. 2021), flowering time (Hong et al. 2021), and host plant resistance to pathogens (He et al. 2020). As an example, for successful infection, pathogens deploy effector proteins into host plant tissue to target proteins and thereby suppress the host immune response. Some effectors target host proteins that are crucial for successful host-pathogen interactions; these plant proteins are often called susceptibility factors (Van Schie and Takken 2014). 


\section{RR Vetukuri et al.}

In transgenic potato, silencing of five susceptibility factors led to reduced late blight disease, caused by Phytophthora infestans (Sun et al. 2016). Similarly, knockout of DOWNY MILDEW RESISTANT 6 (DMR6) in sweet basil (Ocimum basilicum) resulted in up to $93 \%$ reduction in downy mildew pathogen biomass (Hasley et al. 2021). SIGS of these susceptibility factors would be a good non-GM alternative for pest control. Furthermore, there is also the possibility that a GM crop plant where a gene encoding a negative regulator has been knocked out will also have an undesirable impact on plant performance. More precise timing of knock down of the target gene mRNA may avoid the undesirable effects, while delivering the desired trait at the time when it is required. In transgenic plants, this could be achieved by inducible gene silencing (Chen et al. 2003, Masclaux et al. 2004, Liu and Yoder 2016). However, this is also a situation where SIGS may be useful, especially in crops that cannot be easily genetically modified through transgenes or gene editing.

\section{SIGS IN CROP PROTECTION}

In addition to mediating a broad range of cellular processes related to growth and development, roles for sRNAmediated RNAi in host-pathogen interactions have been described (Chaloner et al. 2016, Qiao et al. 2021). While most sRNAs function endogenously, some sRNAs move bidirectionally from one species to another and modulate cellular functions of recipient cells by regulating their gene expression through targeted gene silencing (Weiberg et al. 2013, Chaloner et al. 2016, Cai et al. 2018). This cross-kingdom RNAi can be exploited in crop-protection by generating transgenic plants expressing dsRNAs against selected gene targets of pathogens and pests, a phenomenon called host-induced gene silencing (HIGS; Baulcombe 2015). However, the use of HIGS requires transgenes and genetically modified organisms, which may raise concerns among some consumers, particularly in Europe.

This limitation can be overcome by the application of SIGS (Wang and Jin 2017, Koch et al. 2019). SIGS for crop protection is based on recent findings demonstrating that certain plant pathogens and pests can take up externally applied dsRNA/sRNA (Chaloner et al. 2016, Wang et al. 2016), which can then silence target pathogen genes essential for disease development (environmental RNAi). These findings raise the possibility of applying a SIGS-based strategy to improve crop performance. SIGS against pests and pathogens is an innovative and ecofriendly strategy for plant disease control at preharvest and postharvest stages. Moreover, compared to synthetic fungicide-based crop protection strategies, an RNA-based approach promises lower off-target effects, because it is possible to design short nucleotide sequences that are specific to the target genes. Further, with the ongoing rapid expansion of sequence databases, gene sequences that are specific to pests and pathogens can readily be identified.

\section{SIGS to control fungal and oomycete plant pathogens}

In recent years there has been an increasing number of publications that report on exogenous application of dsRNAs on crop plants to decrease disease caused by plant pathogenic fungi, oomycetes, viruses, and insect pests (Dalakouras et al. 2020). These strategies rely on direct uptake of the applied dsRNA by the pest or pathogen, leading to RNAi of the targeted genes. Demonstrations that SIGS can be used to control fungal and oomycete pathogens have been reported for several years. Spray application of detached barley leaves with dsRNAs targeting Fusarium graminearum ergosterol biosynthesis genes (CYP51A, CYP51B, and CYP51C) strongly inhibited fungal growth. Intriguingly, sprayed dsRNAs moved from site of application to different parts of the plant and could inhibit fungal growth at non-sprayed parts of detached leaves (systemic RNAi) (Koch et al. 2016). In another study, dsRNAs targeting ARGONAUTE and DICER genes in F. graminearum protected barley leaves from infection (Werner et al. 2020).

Similarly, SIGS against Sclerotinia sclerotium and Botrytis cinerea on oilseed rape and Arabidopsis thaliana, and against F. asiaticum on wheat resulted in reduced fungal disease (McLoughlin et al. 2018, Song et al. 2018). A recent study also showed that SIGS can also be applied against the basidiomycete fungus Rhizoctonia solani to control sheath blight of rice (Qiao et al. 2021). In this study, topical application of dsRNA targeting vesicle trafficking pathway genes DYNACTIN 1 (DCN1) and SUPPRESSOR OF ACTIN 1 (SAC1), or a gene coding for polygalacturonase (a known virulence factor gene of $R$. solani) resulted in a significant reduction of fungal biomass and disease symptoms on rice plants (Qiao et al. 2021). SIGS has also been used to control post-harvest diseases in fruit and berry crops, as well as in vegetables. Exogenous application of dsRNAs or sRNAs targeting $B$. cinerea dicer-like genes (Bc-DCL1 or Bc-DCL2) significantly reduced gray mold disease on tomato, grape, strawberry, lettuce, onion, and rose (Wang et al. 2016). In the downy mildew pathogen, Hyaloperonospora arabidopsidis, mixing dsRNA targeting CELLULOSE SYNTHASE (CESA3), suppressed infection on Arabidopsis, thereby suggesting that SIGS may also be effective against oomycetes (Bilir et al. 2019). 
Using a similar approach, exogenously applied dsRNAs did not lead to RNAi of target genes in the potato late blight pathogen, Phytophthora infestans (Qiao et al. 2021). However, by spray application of dsRNAs onto potato leaves, another study demonstrated that dsRNAs targeting developmentally important pathogen genes coding for guanine-nucleotide binding (G) protein $\beta$-subunit (PiGPB1), haustorial membrane protein (PiHMP1), cutinase (PiCUT3), or endo-1,3(4)- $\beta$ glucanase (PiENDO3) in $P$. infestans can potentially be used as a tool in controlling potato late blight disease (Kalyandurg et al. 2021). These results suggest that the optimal outcomes for SIGS against oomycete pathogens may be strongly influenced by the manner in which the dsRNA is applied. Although dsRNA has high target specificity, it is possible to design dsRNAs that can target multiple groups of pathogens. For instance, dsRNAs derived from the $F$. asiaticum $\beta 2$-tubulin gene are shown to be effective against $F$. asiaticum, B. cinerea, Magnaporthe oryzae, and Colletotrichum truncatum in wheat, cucumber, barley, and soybean, respectively (Gu et al. 2019).

\section{SIGS against insect pests}

The application of RNAi for controlling insect pests has been proposed for over a decade (Baum et al. 2007, Mao et al. 2007). However, the first demonstration of exogenous application of dsRNA against insect pests came from a study where dsRNA targeting an arginine kinase gene was applied on citrus trees and grapevine to control psyllids and sharpshooter pests (Hunter et al. 2012). After this breakthrough, the potential for dsRNAs in insect pest management were demonstrated elsewhere (e.g. Cagliari et al. 2019, Dalakouras et al. 2020). For instance, spray application of Brassica oleracea and Brassica alboglabra leaves with siRNAs targeting the acetylcholine esterase genes AchE1 led to significant mortality of diamondback moth, Plutella xylostella, under both laboratory conditions and in the field (Gong et al. 2013). Similarly, foliar application of dsRNA targeting the Leptinotarsa decemlineata actin gene resulted in significant control of Colorado potato beetle on potato plants (San Miguel and Scott 2016). The result showed that dsRNA applied on potato leaves was stable for at least four weeks under greenhouse conditions (San Miguel and Scott 2016).

While a considerable amount of data have shown that SIGS can control insect pests on crop plants (Zotti and Smagghe 2015, Cagliari et al. 2019, Dalakouras et al. 2020), considerable variation in efficacy was reported. The variation in efficacy is plausibly due to the differences in the feeding behaviour of insects. For instance, pests belonging to orders Coleoptera and Lepidoptera are relatively less susceptible to external dsRNA, possibly because lepidopterans confine the ingested dsRNA to endocytic compartments and hemipterans release nucleases into the plant tissue before sucking (Lomate and Bonning 2016, Shukla et al. 2016). Finding suitable delivery methods will be therefore crucial to improve the efficacy of SIGS, as after ingestion dsRNA must survive the degradation by salivary nucleases in the midgut or hemolymph of insect pests. In recent years, various options such as chitosan nanoparticles, cationic core-shell nanoparticles, and guanylated polymers have been explored to develop stable insecticidal dsRNA formulations (Joga et al. 2016, Vélez and Fishilevich 2018). In addition, understanding the mechanisms underlying the systemic spread of ingested dsRNAs to distant cells will further enhance the application of SIGS for insect pest control.

\section{SIGS to control viral pathogens}

Topical application of virus-specific dsRNAs to protect plants against plant viruses has been demonstrated (Mitter et al. 2017a, Dalakouras et al. 2020, Das and Sherif 2020). This was first shown against Pepper mild mottle virus (PMMoV), Alfalfa mosaic virus (AMV) and Tobacco etch virus (TEV) where mechanical application of dsRNA derived from viral sequences targeting replicase genes attenuated viral infections of the respective host plants (Tenllado and Díaz-Ruíz 2001). Since then, more investigations have reported external application of dsRNA to confer viral resistance in various host plants and against a pleothora of viruses (Mitter et al. 2017a, Dubrovina and Kiselev 2019, Dalakouras et al. 2020, Das and Sherif 2020).

\section{dsRNA persistence and uptake are major considerations}

Despite the success of SIGS in controlling fungal and oomycete plant diseases, its application is limited against certain phytopathogenic fungi. Furthermore, the determing factors for effective SIGS against a broad range of plant pathogens still remain to be determined, such as efficacy of exogenous RNA uptake by these organisms. For example, a recent study by Qiao et al. (2021) reported a varied level of dsRNA uptake among the pathogenic fungi such as Aspergillus niger, B. cinera, S. sclerotiorum, Verticillium dahliae (Ascomycota), R. solani (Basidiomycota), and the mycoparasitic fungus 


\section{RR Vetukuri et al.}

Trichoderma virens (Qiao et al. 2021). Moreover, a study on Zymoseptoria tritici (a major fungal pathogen of wheat) and Colletotrichum gloeosporioides (causal agent of anthracnose), showed that these pathogens were incapable of taking up exogenous dsRNA (Kettles et al. 2019, Qiao et al. 2021). The underlying mechanisms associated with variations in RNA uptake remain unknown, but inherent differences including variation in cell wall and plasma membrane composition between different fungal species are hypothesized to be major factors. As efficient dsRNA uptake is vital for successful application of SIGS in plant disease control, investigating dsRNA uptake across a wide range of fungal pathogens is a critical next step in the development of this technology (Qiao et al. 2021).

Despite the potential use of dsRNA in crop protection and improvement, the short-term stability of this type of molecule in the environment is one of the main constraints to practical application. The stability of dsRNA can be increased by developing RNA formulations with nanoparticles that protect the dsRNA/sRNA from degradation (Mitter et al. 2017b). Mixing of a double-layered hydroxide (LDH) nanoparticle with dsRNA molecules (BioClay) resulted in protection of tobacco plants from virus infection for up to 20 days compared with five to seven days using naked dsRNA (Mitter et al. 2017b, Mitter et al. 2017a). Similarly, a preceding application (five days before exposure to aphids) of tobacco and cowpea plants with BioClay formulated dsRNA targeting the coat protein from Bean common mosaic virus inhibited BCMV infection due to aphid-mediated virus transmission (Worrall et al. 2019). Chitosan and carbon dot based nanoparticles have also been used to enhance self-life and uptake of dsRNA (Zhang et al. 2010, Schwartz et al. 2020, Wang et al. 2020). Nanoparticle based formulations promise enhanced delivery of exogenous dsRNAs by increasing their stability and uptake. However, the main concern associated with nanoparticle-based formulation is that they are quite expensive or difficult to synthesize. The efficacy of topically applied dsRNAs can also be affected by the concentration and length of dsRNAs (Dubrovina et al. 2019). Further research in these areas could be helpful for the application and delivery of dsRNAs for RNAi-based plant disease control and improved crop performance.

\section{OUTLOOK}

The growing world population is an important driver for increased food demand that is threatened by production constraints including low yield and diseases. However plant breeding is expensive and time consuming, and also a limited number of traits are accessible to genetic transformation. New traits are sometimes required in a short timeframe to deal with threats such as environmental change, new applications, and emerging pests and pathogens, so urgent solutions are needed. The tools for these solutions need to deliver increased food production, but in a more sustainable manner, with less detrimental environmental impact, and consumer acceptance. SIGS has potential to be used for manipulating plant traits to increase agronomic perfomance and control plant disease development, but more research is needed for development of optimum methods for dsRNA stability, delivery, and reducing the cost for preparation of dsRNA formulation. Furthermore, risk assessments for potential impacts of SIGS on plant health, human health, and the environment need to be undertaken. SIGS has potential to be integrated into integrated pest management (IPM) strategies aiming to both increase crop yields and pest control. Topical application of dsRNAs to modulate crop traits also suggests that dsRNAs may be applied singly or in combinations, allowing 'tuning' of crop traits to best fit the growing conditions. SIGS may be a valuable addition to the precision farming toolbox in the near future.

\section{ACKNOWLEDGEMENTS}

This work has been supported by FORMAS (2019-01316), The Swedish Research Council (2019-04270), NKJ-SNS Dialogue Biocontrol network (NKJ-SNS 06), Carl Tryggers Stiftelse för Vetenskaplig Forskning (CTS 20:464), The Crafoord foundation (20200818), Partnerskap Alnarp (1317/Trg,VO/2020, 1353/VO/2021) and Alnarp stipendiekommitténs. MD was supported by FORMAS (2018-01420) and Carl Tryggers foundation (19:82). SCW acknowledges financial support from the Scottish Government Rural and Environment Science and Analytical Services Division (RESAS). The authors have no conflicts of interest to declare.

\section{REFERENCES}

Baulcombe DC (2015) VIGS, HIGS and FIGS: Small RNA silencing in the interactions of viruses or filamentous organisms with their plant hosts. Current Opinion in Plant Biology 26: 141-146.

Baum JA, Bogaert T, Clinton W, Heck GR, Feldmann P, Ilagan O, Johnson S, Plaetinck G, Munyikwa T, Pleau M, Vaughn T and Roberts J (2007) Control of coleopteran insect pests through RNA interference. Nature Biotechnology 25: 1322-1326. 
Spray-induced gene silencing: an innovative strategy for plant trait improvement and disease control

Bilir Ö, Telli O, Norman C, Budak H, Hong Y and Tör M (2019) Small RNA inhibits infection by downy mildew pathogen Hyaloperonospora arabidopsidis. Molecular Plant Pathology 20: 1523-1534.

Cagliari D, Dias NP, Galdeano DM, dos Santos EÁ, Smagghe G and Zotti MJ (2019) Management of pest insects and plant diseases by nontransformative RNAi. Frontiers in Plant Science 10: 1319.

Cai Q, Qiao L, Wang M, He B, Lin FM, Palmquist J, Huang S Da and Jin $H$ (2018) Plants send small RNAs in extracellular vesicles to fungal pathogen to silence virulence genes. Science 360: 1126-1129.

Castel SE and Martienssen RA (2013) RNA interference in the nucleus: Roles for small RNAs in transcription, epigenetics and beyond. Nature Reviews Genetics 14: 100-112.

Chaloner T, van Kan JAL and Grant-Downton RT (2016) RNA ‘nformation Warfare' in pathogenic and mutualistic interactions. Trends in Plant Science 21: 738-748.

Chen S, Hofius D, Sonnewald U and Börnke F (2003) Temporal and spatial control of gene silencing in transgenic plants by inducible expression of double-stranded RNA. Plant Journal 36: 731-740.

Dalakouras A, Wassenegger M, Dadami E, Ganopoulos I, Pappas ML and Papadopoulou K (2020) Genetically modified organism-free RNA interference: Exogenous application of RNA molecules in plants. Plant Physiology 182: 38-50.

Dalakouras A, Wassenegger Michèle, McMillan JN, Cardoza V, Maegele I, Dadami E, Runne M, Krczal G and Wassenegger M (2016) Induction of silencing in plants by high-pressure spraying of in vitro-synthesized small RNAs. Frontiers in Plant Science 7: 1327.

Das PR and Sherif SM (2020) Application of exogenous dsRNAs-induced RNAi in agriculture: Challenges and triumphs. Frontiers in Plant Science 11: 946.

Ding S-W (2010) RNA-based antiviral immunity. Nature Reviews Immunology 10: 632-644.

Dubrovina AS and Kiselev KV (2019) Exogenous RNAs for gene regulation and plant resistance. International Journal of Molecular Sciences 20: 2282.

Dubrovina AS, Aleynova OA, Kalachev AV, Suprun AR, Ogneva ZV and Kiselev KV (2019) Induction of transgene suppression in plants via external application of synthetic dsRNA. International Journal of Molecular Sciences 7: 1585.

Feng Y, Wang Y, Zhang G, Gan Z, Gao M, Lv J, Wu T, Zhang X, Xu X, Yang S and Han Z (2021) Group-C/S1 bZIP heterodimers regulate MdIPT5b to negatively modulate drought tolerance in apple species. Plant Journal: for Cell and Molecular Biology. DOI: 10.1111/tpj.15296.

Ghildiyal M and Zamore PD (2009) Small silencing RNAs: an expanding universe. Nature Reviews Genetics 10: 94-108.

Gong L, Chen Y, Hu Z and Hu M (2013) Testing insecticidal activity of novel chemically synthesized siRNA against Plutella xylostella under laboratory and field conditions. PLoS ONE 8: e62990.
Gu KX, Song XS, Xiao XM, Duan XX, Wang JX, Duan YB, Hou YP and Zhou MG (2019) A $\beta 2$-tubulin dsRNA derived from Fusarium asiaticum confers plant resistance to multiple phytopathogens and reduces fungicide resistance. Pesticide Biochemistry and Physiology 153: 36-46.

Hasley JAR, Navet N and Tian M (2021) CRISPR/Cas9-mediated mutagenesis of sweet basil candidate susceptibility gene ObDMR6 enhances downy mildew resistance. PLOS One 16: e0253245.

He Q, McLellan H, Boevink PC and Birch PRJ (2020) All roads lead to susceptibility: The many modes of action of fungal and oomycete intracellular effectors. Plant Communications 1: 100050.

Holoch D and Moazed D (2015) RNA-mediated epigenetic regulation of gene expression. Nature Reviews Genetics 16: 71-84.

Hong L, Niu F, Lin Y, Wang S, Chen L and Jiang L (2021) MYB117 is a negative regulator of flowering time in Arabidopsis. Plant Signaling \& Behavior 16. DOI: 10.1080/15592324.2021.1901448.

Hunter WB, Glick E, Paldi N and Bextine BR (2012) Advances in RNA interference: DsRNA treatment in trees and grapevines for insect pest suppression. Southwestern Entomologist 37: 85-87.

Jiang L, Ding L, He B, Shen J, Xu Z, Yin M and Zhang X (2014) Systemic gene silencing in plants triggered by fluorescent nanoparticle-delivered double-stranded RNA. Nanoscale 6: 9965-9969.

Joga MR, Zotti MJ, Smagghe G and Christiaens O (2016) RNAi efficiency, systemic properties, and novel delivery methods for pest insect control: What we know so far. Frontiers in Physiology 7: 553.

Kalyandurg PB, sundararajan P, Dubey M, Ghadamgahi F, Zahid MA, Whisson S and Vetukuri RR (2021) Spray-induced gene silencing as a potential tool to control potato late blight disease. Phytopathology. DOI: 10.1094/phyto-02-21-0054-sc.

Ketting RF (2011) The many faces of RNAi. Developmental Cell 20: 148-161.

Kettles GJ, Hofinger BJ, Hu P, Bayon C, Rudd JJ, Balmer D, Courbot M, Hammond-Kosack KE, Scalliet G and Kanyuka K (2019) sRNA profiling combined with gene function analysis reveals a lack of evidence for cross-kingdom RNAi in the wheat-Zymoseptoria tritici pathosystem. Frontiers in Plant Science 10: 892.

Koch A, Biedenkopf D, Furch A, Weber L, Rossbach O, Abdellatef E, Linicus L, Johannsmeier J, Jelonek L, Goesmann A, Cardoza V, McMillan J, Mentzel T and Kogel KH (2016) An RNAi-based control of Fusarium graminearum infections through spraying of long dsRNAs involves a plant passage and is controlled by the fungal silencing machinery. PLoS Pathogens 12: e1005901.

Koch A, Höfle L, Werner BT, Imani J, Schmidt A, Jelonek L and Kogel KH (2019) SIGS vs HIGS: a study on the efficacy of two dsRNA delivery strategies to silence Fusarium FgCYP51 genes in infected host and non-host plants. Molecular Plant Pathology 20: 1636-1644.

Lau SE, Schwarzacher T, Othman RY and Harikrishna JA (2015) dsRNA silencing of an R2R3-MYB transcription factor affects flower cell shape in a Dendrobium hybrid. BMC Plant Biology 15: 1-14. 
Li H, Guan R, Guo H and Miao X (2015) New insights into an RNAi approach for plant defence against piercing-sucking and stem-borer insect pests. Plant Cell and Environment 38: 2277-2285.

Li W, Wang Y, Li R, Chang X, Yuan X and Jing R (2021) Cloning and characterization of TaSAP7-A, a member of the stress-associated protein family in common wheat. Frontiers in Plant Science 12: 340.

Liu S and Yoder JI (2016) Chemical induction of hairpin RNAi molecules to silence vital genes in plant roots. Scientific Reports 6: 1-11.

Lomate PR and Bonning BC (2016) Distinct properties of proteases and nucleases in the gut, salivary gland and saliva of southern green stink bug, Nezara viridula. Scientific Reports 6: 1-10.

Mao YB, Cai WJ, Wang JW, Hong GJ, Tao XY, Wang LJ, Huang YP and Chen XY (2007) Silencing a cotton bollworm P450 monooxygenase gene by plant-mediated RNAi impairs larval tolerance of gossypol. Nature Biotechnology 25: 1307-1313.

Masclaux F, Charpenteau M, Takahashi T, Pont-Lezica R and Galaud JP (2004) Gene silencing using a heat-inducible RNAi system in Arabidopsis. Biochemical and Biophysical Research Communications 321: 364-369.

McLoughlin AG, Wytinck N, Walker PL, Girard IJ, Rashid KY, De Kievit T, Fernando WGD, Whyard S and Belmonte MF (2018) Identification and application of exogenous dsRNA confers plant protection against Sclerotinia sclerotiorum and Botrytis cinerea. Scientific Reports 8: 7320.

Melnyk CW, Molnar A and Baulcombe DC (2011) Intercellular and systemic movement of RNA silencing signals. EMBO Journal 30: 3553-3563.

Mermigka G, Verret F and Kalantidis K (2016) RNA silencing movement in plants. Journal of Integrative Plant Biology 58: 328-342.

Min J-H, Park C-R, Chung J-S and Kim CS (2021) Arabidopsis thaliana ubiquitin-associated protein 1 (AtUAP1) interacts with Arabidopsis thaliana ring zinc finger 1 (AtRZF1) to negatively regulate dehydration response. Plant and Cell Physiology. DOI: 10.1093/pcp/pcab082.

Mitter N, Worrall EA, Robinson KE, Li P, Jain RG, Taochy C, Fletcher SJ, Carroll BJ, Lu GQ and Xu ZP (2017b) Clay nanosheets for topical delivery of RNAi for sustained protection against plant viruses. Nature Plants 3: 16207.

Mitter N, Worrall EA, Robinson KE, Xu ZP and Carroll BJ (2017a) Induction of virus resistance by exogenous application of double-stranded RNA. Current Opinion in Virology 26: 49-55.

Myo T, Wei F, Zhang H, Hao J, Zhang B, Liu Z, Cao G, Tian B and Shi G (2021) Genome-wide identification of the BASS gene family in four Gossypium species and functional characterization of GhBASSs against salt stress. Scientific Reports 11: 11342.

Numata K, Ohtani M, Yoshizumi T, Demura T and Kodama Y (2014) Local gene silencing in plants via synthetic dsRNA and carrier peptide. Plant Biotechnology Journal 12: 1027-1034.

Qiao L, Lan C, Capriotti L, Ah-Fong A, Nino Sanchez J, Hamby R, Heller J, Zhao H, Louise Glass N, Judelson HS, Mezzetti B, Niu D and Jin H (2021)
Spray-induced gene silencing for disease control is dependent on the efficiency of pathogen RNA uptake. Plant Biotechnology Journal. DOI: 10.1111/pbi.13589.

Rosa C, Kuo YW, Wuriyanghan H and Falk BW (2018) RNA interference mechanisms and applications in plant pathology. Annual Review of Phytopathology 56: 581-610.

Sammons R, Ivashuta S, Liu H, Wang D, Feng P, Kouranov A and Andersen $S$ (2011) Polynucleotide molecules for gene regulation in plants. U.S. Patent 2011/0296556 A1

San Miguel K and Scott JG (2016) The next generation of insecticides: dsRNA is stable as a foliar-applied insecticide. Pest Management Science 72: 801-09.

Schwartz SH, Hendrix B, Hoffer P, Sanders RA and Zheng W (2020) Carbon dots for efficient small interfering RNA delivery and gene silencing in plants. Plant Physiology 184: 647-657.

Shukla JN, Kalsi M, Sethi A, Narva KE, Fishilevich E, Singh S, Mogilicherla K and Palli SR (2016) Reduced stability and intracellular transport of dsRNA contribute to poor RNAi response in lepidopteran insects. RNA Biology 13: 656-669.

Song XS, Gu KX, Duan XX, Xiao XM, Hou YP, Duan YB, Wang JX and Zhou MG (2018) A myosin5 dsRNA that reduces the fungicide resistance and pathogenicity of Fusarium asiaticum. Pesticide Biochemistry and Physiology 150: 1-9.

Sparks TC and Lorsbach BA (2017) Perspectives on the agrochemical industry and agrochemical discovery. Pest Management Science 73: 672-677.

Sun K, Wolters AMA, Vossen JH, Rouwet ME, Loonen AEHM, Jacobsen E, Visser RGF and Bai Y (2016) Silencing of six susceptibility genes results in potato late blight resistance. Transgenic Research 25: 731-742.

Tenllado F and Díaz-Ruíz JR (2001) Double-stranded RNA-mediated interference with plant virus infection. Journal of Virology 75: 12288-12297.

UN - United Nations, Department of Economic and Social Affairs, Population Division (2019) World population prospects 2019: Highlights. United Nations, New York, 46p. (ST/ESA/SER.A/423).

Valin $H$, Sands RD, van der Mensbrugghe D, Nelson GC, Ahammad H, Blanc E, Bodirsky B, Fujimori S, Hasegawa T, Havlik P, Heyhoe E, Kyle $P$, Mason-D'Croz D, Paltsev S, Rolinski S, Tabeau A, van Meijl H, von Lampe $M$ and Willenbockel D (2014) The future of food demand: Understanding differences in global economic models. Agricultural Economics (United Kingdom) 45: 51-67.

Van Schie CCN and Takken FLW (2014) Susceptibility genes 101: How to be a good host. Annual Review of Phytopathology 52: 551-581.

Vélez AM and Fishilevich E (2018) The mysteries of insect RNAi: A focus on dsRNA uptake and transport. Pesticide Biochemistry and Physiology 151: 25-31.

Wang K, Peng Yingchuan, Chen J, Peng Yue, Wang X, Shen Z and Han $Z$ (2020) Comparison of efficacy of RNAi mediated by various 
Spray-induced gene silencing: an innovative strategy for plant trait improvement and disease control

nanoparticles in the rice striped stem borer (Chilo suppressalis). Pesticide Biochemistry and Physiology 165. DOI: 10.1016/j. pestbp.2019.10.005.

Wang $M$ and Jin $H$ (2017) Spray-induced gene silencing: a powerful innovative strategy for crop protection. Trends in Microbiology 25: 4-6.

Wang M, Weiberg A, Lin FM, Thomma BPHJ, Huang H Da and Jin H (2016) Bidirectional cross-kingdom RNAi and fungal uptake of external RNAs confer plant protection. Nature Plants 2. DOI: 10.1038/ NPLANTS.2016.151

Weiberg A, Wang M, Lin FM, Zhao H, Zhang Z, Kaloshian I, Huang H Da and Jin $H$ (2013) Fungal small RNAs suppress plant immunity by hijacking host RNA interference pathways. Science 342: 118-123.

Werner BT, Gaffar FY, Schuemann J, Biedenkopf D and Koch AM (2020) RNA-spray-mediated silencing of Fusarium graminearum AGO and DCL genes improve barley disease resistance. Frontiers in Plant
Science 11: 476.

Worrall EA, Bravo-Cazar A, Nilon AT, Fletcher SJ, Robinson KE, Carr JP and Mitter N (2019) Exogenous application of RNAi-inducing doublestranded RNA inhibits aphid-mediated transmission of a plant virus. Frontiers in Plant Science 10: 265.

Younis A, Siddique MI, Kim CK and Lim KB (2014) RNA interference (RNAi) induced gene silencing: A promising approach of hi-tech plant breeding. International Journal of Biological Sciences 10: 1150-1158.

Zhang X, Zhang J and Zhu KY (2010) Chitosan/double-stranded RNA nanoparticle-mediated RNA interference to silence chitin synthase genes through larval feeding in the African malaria mosquito (Anopheles gambiae). Insect Molecular Biology 19: 683-693.

Zotti MJ and Smagghe G (2015) RNAi technology for insect management and protection of beneficial insects from diseases: Lessons, challenges and risk assessments. Neotropical Entomology 44: 197-213. 